\title{
Effectiveness of a tailored neck training program on neck strength, movement, and fatigue in under- 19 male rugby players: a randomized controlled pilot study
}

\author{
This article was published in the following Dove Press journal: \\ Open Access Journal of Sports Medicine \\ 5 May 2015 \\ Number of times this article has been viewed
}

\author{
Matthew D Barrett ${ }^{\prime}$ \\ Terence F McLoughlin ${ }^{2}$ \\ Kieran R Gallagher' \\ Don Gatherer ${ }^{3}$ \\ Michael TR Parratt ${ }^{\prime}$ \\ Jonathan R Perera' \\ Tim WR Briggs' \\ 'Royal National Orthopaedic \\ Hospital, Stanmore, Middlesex, \\ United Kingdom; ${ }^{2}$ Royal Liverpool \\ University Hospital, Liverpool, \\ Mersey Deanery, United Kingdom; \\ ${ }^{3}$ The Gatherer Partnership, Aylesbury, \\ United Kingdom
}

\begin{abstract}
Purpose: To investigate the effect of a tailored neck muscle conditioning program on neck muscle strength, neck muscle fatigue, and range of neck movement in 16-18-year-old male rugby players.
\end{abstract}

Materials and methods: Thirty-four male rugby players were divided into forward and back playing positions and randomized within these groups. Seventeen players were randomly assigned to each group. The test group was given a tailored 6-week exercise regime based on their baseline measurements to be performed three times a week in addition to their normal training and playing. The control group trained and played as normal. The outcome measures used were cervical spine range of movement, neck strength, and neck muscle fatigability.

Results: There were no clinically relevant statistically significant differences between the two groups. Trends identified between the two groups suggest that a tailored neck exercise program increases neck strength, particularly neck extension, and increases resistance to fatigue, as well as influencing right- and left-sided neck muscle balance. A reduction in range of movement was also demonstrated in the test group. There was a great deal of variability in range of movement and strength within this age group. No previously undiagnosed neck conditions were detected, and there were no adverse events reported.

Conclusion: This study has shown that neck strength, range of movement, and susceptibility of the neck muscles to fatigue can be influenced using a focused neck training regime. It forms an important basis for a larger, multicenter study to ensure the neck is given due attention in rugby training and receives the same focus of conditioning as other parts of the body.

Keywords: injury, sport, muscle, youth, scrum

\section{Introduction}

Since the advent of professional rugby in 1995, the prevalence of injuries in the game has risen exponentionally. ${ }^{1-3}$ It has been shown that professional rugby union carries a higher incidence of injury compared with other sports, ${ }^{4}$ and furthermore, recent studies suggest this has become an increasing problem in youth rugby. ${ }^{5,6}$ Although injuries in youth rugby occur less frequently than in the adult game, the risk for injury and its severity have been shown to increase with age. ${ }^{5}$ Injuries to the head and neck account for between $14 \%$ and $29 \%$ of rugby injuries. ${ }^{2,7-9}$ The scrum has reasonably been assumed to be the area of the game in which the majority of neck injuries occur; however, the tackle has also been shown to be a source of such injuries. ${ }^{7,10-14}$ There is variation in injury pattern between the two codes of rugby, with scrums being the most common circumstance of injury in rugby union, and the tackle situation in rugby league. ${ }^{15}$ As
Correspondence: Matthew David Barrett Royal National Orthopaedic Hospital, Brockley Hill, Stanmore, Middlesex, HA74LP, United Kingdom Email mbarrett24@gmail.com 
the game has evolved, so has the musculoskeletal intensification of conditioning, with a presumed commensurate increase in the forces involved in the tackle. The necessary adjustments to the technique of tackling have not necessarily developed to allow for these forces.

Catastrophic events occur rarely in sport. ${ }^{16}$ However, up until the third decade of life, sport accounts for a large proportion of all catastrophic spinal injuries, and collision sports, such as rugby, are responsible for a significant number of these injuries. ${ }^{17-19}$ The International Rugby Board's definition of a "catastrophic injury" includes spinal cord injuries with an American Spinal Injury Association classification at 12 months of A-D: A = complete: no motor or sensory function is preserved in the sacral segments $\mathrm{S} 4-\mathrm{S} 5$, and D = incomplete: motor function is preserved below the neurological level, and at least half of the key muscles below the neurological level have a muscle grade of 3 or more. ${ }^{20}$ The English Rugby Football Union classifies a nonfatal catastrophic injury as a brain or spinal cord injury that results in permanent ( $>12$ months) severe functional disability. ${ }^{21}$ The term very serious injury is used until the criteria for catastrophic injury are met. Severe functional disability is defined by the World Health Organization as a loss of more than $50 \%$ of the capability of the structure. The cost of catastrophic spinal injuries to the National Health Service is currently unknown. The risk for catastrophic injury in the professional rugby game has been reported to be 0.8 per 1,000 playing hours. $^{5}$

In England alone, there are estimated to be more than 2 million under 19s (participants younger than 19 years) playing rugby at school. The incidence of adolescents taking up the game is rising, and therefore it appears more likely than not that rugby-related injuries, including those to the neck, will become even more prevalent. There is little in the literature relating to musculoskeletal maturity and neck strength in the under-19 age group. Hamilton et al demonstrated that there is a wide variation in neck strength at each age group across the whole range of the school population. ${ }^{22}$ In England, rugby players in schools are differentiated by age only, not by their physical attributes such as weight, height, or body mass index. Current training programs in rugby focus on building limb and upper body strength while largely ignoring the neck. This is at variance with the known vulnerability of the neck in rugby and the potential for catastrophic injury to this area.

\section{Objective}

The primary aim of this study was to highlight that the neck should receive the same attention as other parts of the musculoskeletal system in rugby training and conditioning and to investigate whether a tailored neck muscle conditioning program has any effect on neck muscle strength, neck muscle fatigue, and range of neck movement in 16-18-yearold male rugby players. The second aim was to identify players either with undiagnosed neck conditions or gross neck muscle imbalance who might be potentially at increased risk for neck injury. It was hoped that a better understanding could be obtained of what could be considered "normal" neck strength and range-of-movement profile in this age group of rugby players.

\section{Materials and methods Study design}

A prospective, randomized controlled trial was performed to investigate the effect of a tailored neck muscle conditioning program on neck strength and range of movement in 16-18year-old male rugby players.

\section{Participants}

All senior rugby players at a male rugby-playing secondary school were invited to take part in the study. An initial meeting was set up at the school, where the investigative team introduced the study to players and staff. Thirty-nine players attended. To be included in the study, the subjects had to be male, between 16 and 18 years of age, and currently involved in the school senior rugby set up, with the expectation of being so for the duration of the study. Participation was entirely voluntary, and players were not provided with any incentives to participate. Written consent was obtained from the parent or guardian or the players themselves if they were aged 18 years at the time of recruitment. A total of 36 players were entered into the study. Any player with an existing or previous neck injury was excluded. This information was provided in the prestudy material and checked during the enrolment paperwork and before undertaking any testing. The players were divided into two groups according to playing position: backs (scrum half, fly half, center winger, full back) and forwards (prop, hooker, second row, flanker, number eight). This was done to ensure that forwards and backs were represented in comparative numbers in the test and control groups. After enrolment and initial data collection, players were randomized into either the test group or the control group by their selecting an identical opaque envelope containing either "test" or "control" cards. The randomization was overseen by the lead investigator (MDB). It was performed within the playing position groups (17 backs and 19 forwards). Thirty-eight identical opaque envelopes 
containing a card with either "test" or "control" were used: 18 (nine test; nine control) of these were used in the backs group, and 20 (ten test; ten control) in the forwards group. It was performed in this way to ensure comparable allocation with playing position groups to the test and control groups. Figure 1 shows the flow diagram for player enrolment and group allocation.

\section{Study settings}

The study took place in Bedford School, Bedford, Bedfordshire, from January 2012 to May 2012.

\section{Ethics}

Ethical approval was received from the National Research Ethics Service.

\section{Intervention}

Players in the test group were given a 6-week individualized, tailored exercise regime according to their baseline measurements. Each player was given a head harness (Figure 2) and custom elastic cords that provide variable load against resistance. The regimes were devised and overseen by a senior sports physiotherapist (DG). The head of sport at Bedford School supervised the players on a weekly basis and was in regular contact with the senior sports physiotherapist. Before starting, the regime and exercises were explained in detail and demonstrated to the players. All players in the intervention group underwent 2 weeks of supervised familiarization and technique acquisition with the senior sports physiotherapist and the head of sport before starting their 6 -week program. The date for start of training was defined by the school schedule and the identified retest date. This ensured that all players in the intervention group had sufficient time to undergo familiarization and 6 weeks of training and to undergo retesting within 2 weeks of completion.

The regime consisted of eight exercises that were to be performed three times a week, in addition to the player's normal training and playing routine. Instructions were provided for each exercise, which included warm-up repetitions and load, speed of movement, rest between sets, range of movement, number of sets to be completed, repetitions per set, and load (kilograms) per set. Exercise construction is shown in Figure 3. Exercise details, explaining how players were to safely increase the load used for the exercises, are shown in Figure 4.

A progression chart was completed during each exercise by the players (Figure 5). Players in the control group trained and played as normal.

\section{Data}

Players' reference points of age (years, months), height (centimeters), weight (kilograms), playing position (forward/back),

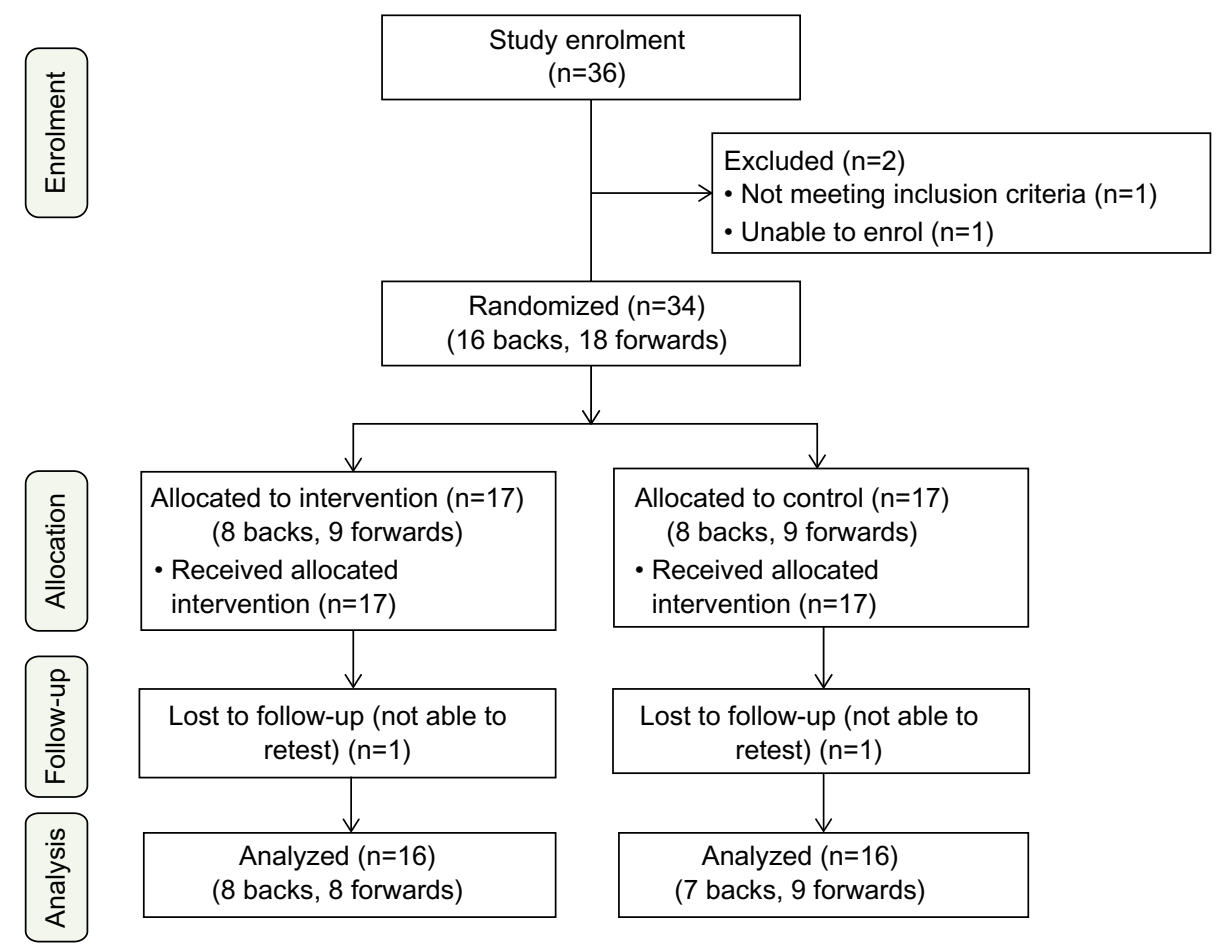

Figure I Study flow diagram. 


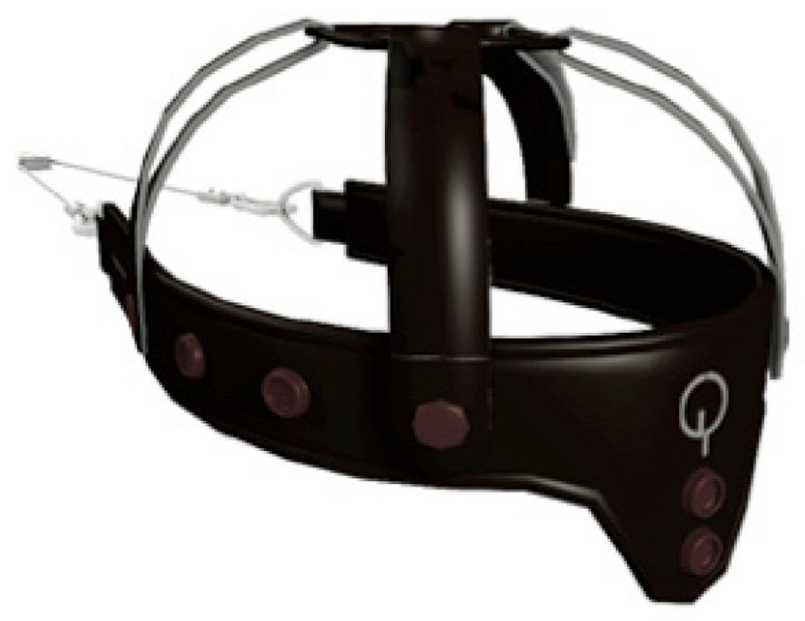

Figure 2 Gatherer Systems ${ }^{\mathrm{TM}}$ head harness.

and neck circumference were recorded at the start and end of the study. Assessments were made of cervical spine range of movement, neck muscle strength, and neck muscle fatigability. Neck range of movement was measured using a CROM Deluxe Instrument (Cervical Range of Motion Instrument; Performance Attainment Associates, Minneapolis, MN, USA; Figure 6).

\section{Neck strength measurement}

Maximal voluntary isometric cervical muscle strength was assessed using a GS Gatherer, a bespoke wireless load cell that allows measurement of force up to $250 \mathrm{~kg}$ at a rate of
$20 \mathrm{~Hz}$, along with the GS Harness (Figure 2), a universal head harness that allows dynamic rotational loading of the neck (Gatherer Systems, Aylesbury, United Kingdom). This system has been demonstrated to show good repeatability and intratester reliability when assessing isometric neck strength. ${ }^{23}$ Contralateral (right vs left), antagonistic (flexion vs extension), and fatigue assessments were performed, recorded in kilograms. Contralateral assessments of neck flexion and extension with right and left rotation and side flexion, and antagonistic assessments of neck flexion and extension, were recorded (Figure 7).

The fatigue assessment was performed on neck extension, based on the principle of accumulation fatigue. Isometric testing was used, where the subject held a position until failure against a target load of $50 \%$ of their previously recorded extension one isometric voluntary contraction maxima test score (1IVMCmax). The safety cut off level was set at $80 \%$ of target load, whereby the test stops automatically if the force falls below the cut off or more than 4 seconds. Fatigue was recorded in time (seconds), and the area below the curve was recorded as load (kilograms) multiplied by seconds (Figure 8). All measurements were recorded using the GS Analysis Suite (Gatherer Systems).

The test was ended at the moment muscle force was measured to peak. Each test was carried out three times, and the average of the peak forces of all three tests was calculated to give the mean peak force score. With fatigue,

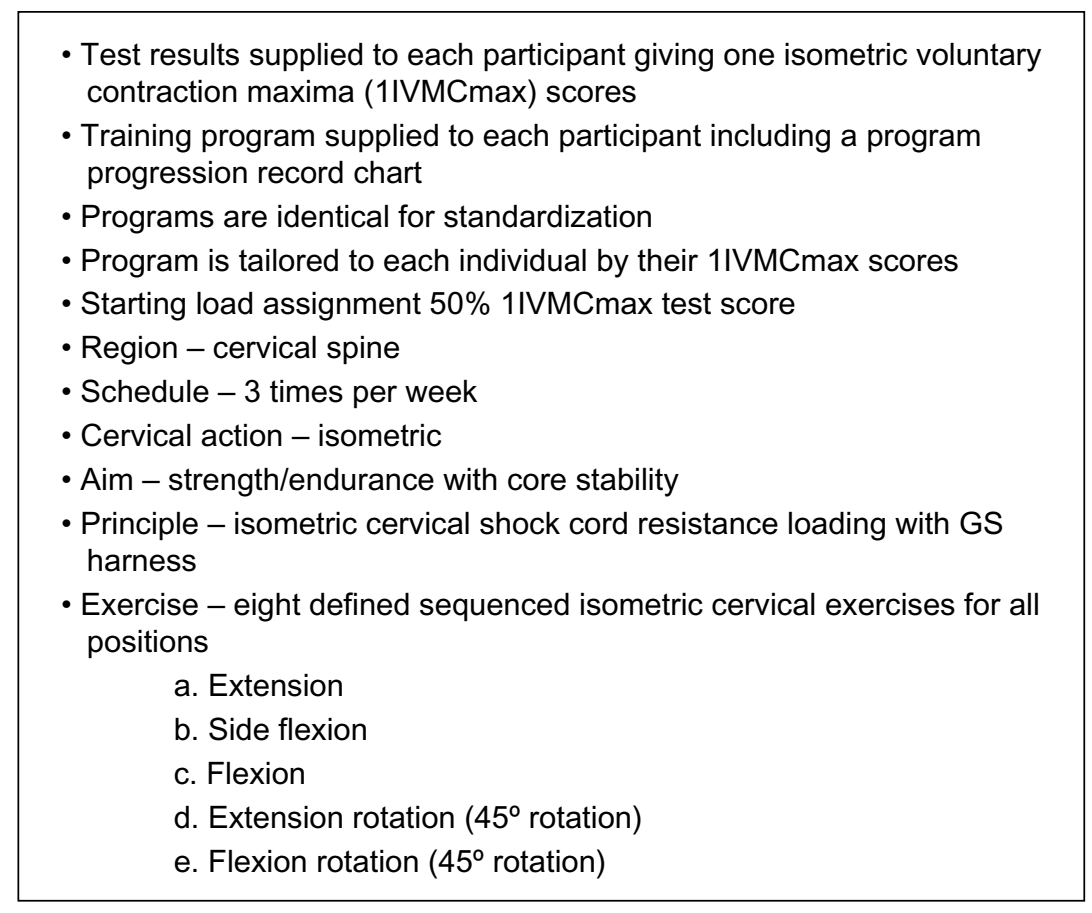

Figure 3 Exercise construction. Abbreviation: GS, Gatherer Systems ${ }^{\mathrm{TM}}$. 
- Light warm up/pre exercise familiarisation

- Speed of movement - 2-1-2-1 seconds

- Rest between sets -30 seconds

- Cervical action - isometric

- Sets -4

- Reps per set -6

- Load assignment $-50 \%$ IIVMCmax

- Progression $-\max +/-3$. Continuous progress monitoring. Last set repetition progression is defined so if the

last rep target is exceeded by plus 3 reps - increase the load next time - and decrease if the target rep is not completed by more than minus 3 reps

\begin{tabular}{|c|c|c|c|c|c|c|c|c|c|}
\hline Number & Exercise & $\begin{array}{l}\text { Warm } \\
\text { up rep }\end{array}$ & $\begin{array}{l}\text { Warm up } \\
\text { load kgs }\end{array}$ & $\begin{array}{l}\text { Speed of } \\
\text { movement }\end{array}$ & \begin{tabular}{|c|} 
Rest \\
between \\
sets \\
\end{tabular} & $\begin{array}{c}\text { Range of } \\
\text { movement }\end{array}$ & Set & $\begin{array}{l}\text { Reps } \\
\text { per set }\end{array}$ & $\begin{array}{l}\text { Load Kgs } \\
\text { per set }\end{array}$ \\
\hline 1 & $\begin{array}{l}\text { Head harness bungee, neck extension (isometric) } \\
\text { trunk extension (seated) }\end{array}$ & 8 & Light & $2-1-2-1$ & $\begin{array}{l}30 \\
\text { sec }\end{array}$ & ISO & 4 & 6 & $\begin{array}{l}\text { Start } 50 \% 1 \mathrm{RM} \\
\text { Then } \mathrm{Max}+1-3\end{array}$ \\
\hline 2 & $\begin{array}{l}\text { Head harness bungee, neck side flexion (isometric) } \\
\text { LEFT sideways step keeping neck central }\end{array}$ & 8 & Light & $2-1-2-1$ & $\begin{array}{l}30 \\
\text { sec }\end{array}$ & ISO & 4 & 6 & $\begin{array}{l}\text { Start } 50 \% 1 \mathrm{RM} \\
\text { Then } \mathrm{Max}+/-3\end{array}$ \\
\hline 3 & $\begin{array}{l}\text { Head harness bungee, neck side flexion (isometric) } \\
\text { RIGHT sideways step keeping neck central }\end{array}$ & 8 & Light & $2-1-2-1$ & $\begin{array}{l}30 \\
\text { sec }\end{array}$ & ISO & 4 & 6 & $\begin{array}{l}\text { Start } 50 \% 1 \mathrm{RM} \\
\text { Then } \mathrm{Max}+1-3\end{array}$ \\
\hline 4 & $\begin{array}{l}\text { Head harness bungee, neck flexion (isometric) } \\
\text { trunk flexion (seated) }\end{array}$ & 8 & Light & $2-1-2-1$ & $\begin{array}{l}30 \\
\text { sec }\end{array}$ & ISO & 4 & 6 & $\begin{array}{l}\text { Start } 50 \% 1 \mathrm{RM} \\
\text { Then Max }+/-3\end{array}$ \\
\hline 5 & $\begin{array}{l}\text { Head harness bungee, ROTATED NECK to RIGHT } \\
\text { extension (isometric) trunk extension (seated) }\end{array}$ & 8 & Light & $2-1-2-1$ & $\begin{array}{l}30 \\
\text { sec }\end{array}$ & ISO & 4 & 6 & $\begin{array}{l}\text { Start } 50 \% 1 \mathrm{RM} \\
\text { Then Max }+/-3\end{array}$ \\
\hline 6 & $\begin{array}{l}\text { Head harness bungee, ROTATED NECK to LEFT } \\
\text { extension (isometric) trunk extension (seated) }\end{array}$ & 8 & Light & $2-1-2-1$ & $\begin{array}{l}30 \\
\text { sec }\end{array}$ & ISO & 4 & 6 & $\begin{array}{l}\text { Start } 50 \% 1 \mathrm{RM} \\
\text { Then } \mathrm{Max}+1-3\end{array}$ \\
\hline 7 & $\begin{array}{l}\text { Head harness bungee, ROTATED NECK to RIGHT } \\
\text { flexion (isometric) trunk flexion (seated) }\end{array}$ & 8 & Light & $2-1-2-1$ & $\begin{array}{l}30 \\
\text { sec }\end{array}$ & ISO & 4 & 6 & $\begin{array}{l}\text { Start } 50 \% 1 \mathrm{RM} \\
\text { Then Max }+/-3\end{array}$ \\
\hline 8 & $\begin{array}{l}\text { Head harness bungee, ROTATED NECK to LEFT } \\
\text { flexion (isometric) trunk flexion (seated) }\end{array}$ & 8 & Light & $2-1-2-1$ & $\begin{array}{c}30 \\
\text { sec }\end{array}$ & ISO & 4 & 6 & $\begin{array}{l}\text { Start } 50 \% 1 \mathrm{RM} \\
\text { Then Max }+1-3\end{array}$ \\
\hline
\end{tabular}

Figure 4 Exercise details and table given to each player.

Abbreviations: IRM, one repetition maximum; ISO, isometric; sec, seconds; rep, repetition; IIVMCmax, one isometric voluntary contraction maxima.

only one measurement was recorded. The test was stopped immediately if any pain or neurological symptoms developed.

The investigators undertaking the testing and recording of measurements of players at the start and end of the study period were the same and were supervised by DG. All were blinded as to the player's group allocation.

\section{Outcomes}

The main objective of the study was to investigate the effect of a tailored neck training regime on neck strength, cervical spine range of movement, and neck muscle fatigability. The secondary outcome was to identify players with undiagnosed, existing neck problems, using our assessment tool, and to quantify the "normal" values for neck movement and strength in an age group of young, fit males.

\section{Statistical analysis}

Statistical analysis of the data was performed by an independent statistician from the Medical Research Council Clinical Trials Unit, and subsequent analysis was performed by a second statistician from the University of Bedfordshire because of the unavailability of the first. The two-tailed independent $t$-test was used to compare the approximately normally distributed continuous variables. Where the continuous data were skewed, the Mann-Whitney U test was alternatively used to compare across treatment groups. Fisher's exact test was used to compare categorical variables.

Rehabilitation programme progression record chart

\begin{tabular}{|c|c|c|c|c|c|c|c|c|c|}
\hline Number & Exercise & Date & Cords & Date & Cords & Date & Cords & Date & Cords \\
\hline 1 & $\begin{array}{l}\text { Head harness bungee, neck extension (isometric) } \\
\text { trunk extension (seated) }\end{array}$ & & & & & & & & \\
\hline 2 & $\begin{array}{l}\text { Head harness bungee neck side flexion (isometric) } \\
\text { LEFT sideways step keeping neck central }\end{array}$ & & & & & & & & \\
\hline 3 & $\begin{array}{l}\text { Head harness bungee neck side flexion (isometric) } \\
\text { RIGHT sideways step keeping neck central }\end{array}$ & & & & & & & & \\
\hline 4 & $\begin{array}{l}\text { Head harness bungee, neck flexion (isometric) } \\
\text { trunk flexion (seated) }\end{array}$ & & & & & & & & \\
\hline 5 & $\begin{array}{l}\text { Head harness bungee, ROTATED NECK to RIGHT } \\
\text { extension (isometric) trunk extension (seated) }\end{array}$ & & & & & & & & \\
\hline 6 & $\begin{array}{l}\text { Head harness bungee, ROTATED NECK to LEFT } \\
\text { extension (isometric) trunk extension (seated) }\end{array}$ & & & & & & & & \\
\hline 7 & $\begin{array}{l}\text { Head harness bungee, ROTATED NECK to RIGHT } \\
\text { flexion (isometric) trunk flexion (seated) }\end{array}$ & & & & & & & & \\
\hline 8 & $\begin{array}{l}\text { Head harness bungee, ROTATED NECK to LEFT } \\
\text { flexion (isometric) trunk flexion (seated) }\end{array}$ & & & & & & & & \\
\hline
\end{tabular}

Figure 5 Progression chart provided to each player in the intervention group.

Note: Cords relates to the elastic cords used along with a head harness that provided a variable load against resistance. 


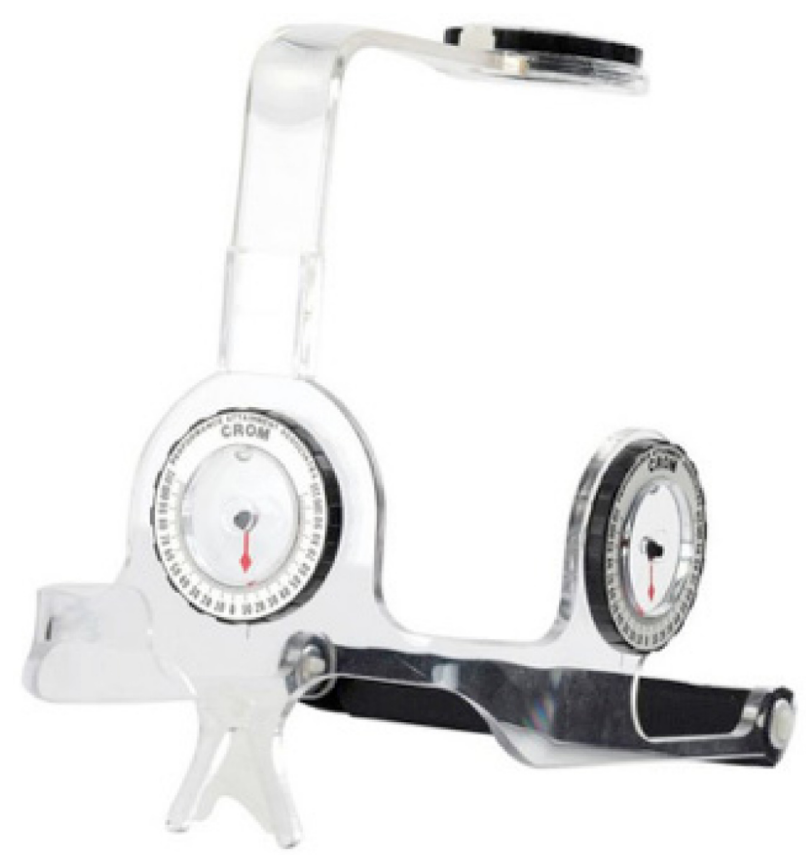

Figure 6 CROM Deluxe instrument.

Missing data were assumed to be missing completely at random; that is, "missingness" did not depend on observed or unobserved measures, and a complete case analysis was performed for each outcome. Under this assumption, a complete case analysis is valid. ${ }^{24}$ Data are summarized as means for continuous (approximate) normally distributed variables, medians for nonnormally distributed variables, and frequencies and percentages for categorical variables.

All statistical analysis was performed using Stata/ IC version 12.1 (StataCorp, College Station, TX, USA). A $P$-value $<0.05$ was considered statistically significant.

\section{Results}

The initial population enrolled in the study consisted of 36 players. One player reported previous neck problems, and one player was unable to complete the initial part of the study because of other commitments. The remaining 34 players were divided into playing position groups of backs (16) and forwards (18). Randomization of the two playing position groups produced 17 players in the test group ( 8 backs, 9 forwards) and 17 players ( 8 backs, 9 forwards) in the control group. The data from 34 boys were analyzed. Two boys (one control and one test) were unable to attend the retesting session at the end of the study and were therefore excluded in the final analysis. The dropout rate was the same for the test and control groups ( $\mathrm{n}=1 ; 5.9 \%)$.

Table 1 shows the pre- and postintervention measurements of height, weight, neck circumference, and neck movements.

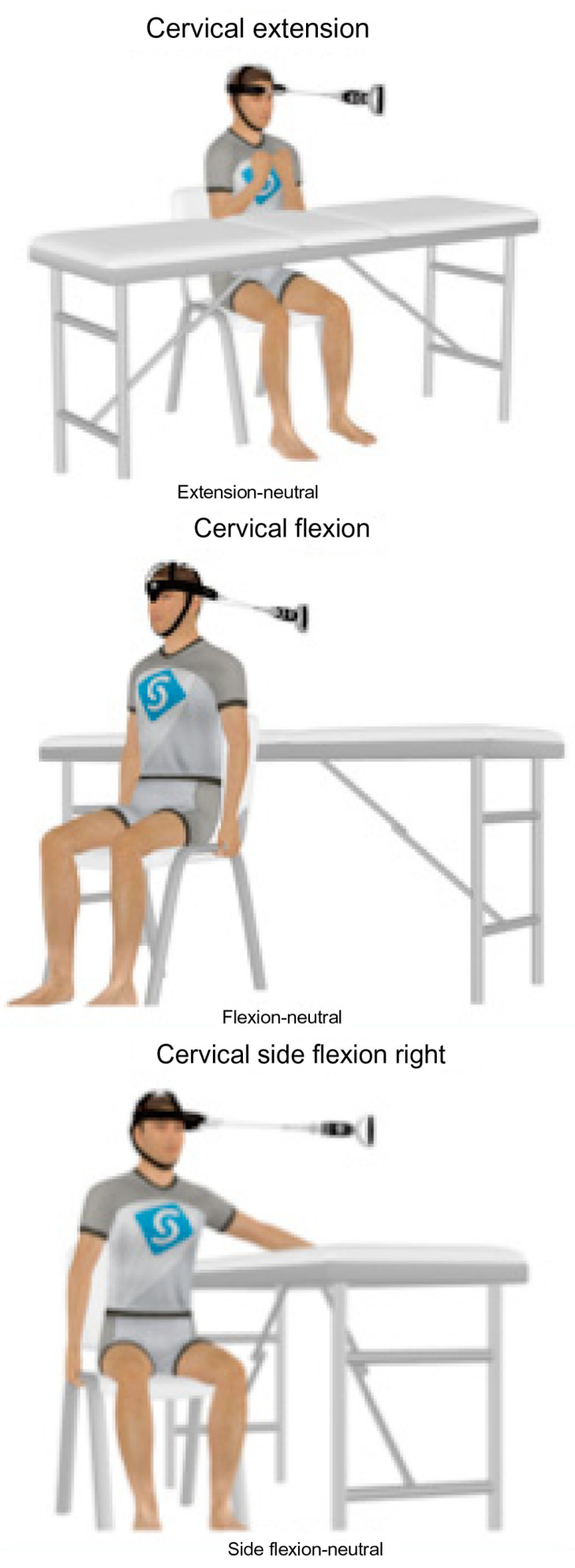

Figure 7 Neck strength assessment: extension, flexion, and right lateral flexion.

The baseline characteristics of the players in the two study groups were similar. The mean age was 17.3 years in the control group and 17.2 years in the test group. There were significant differences in neck flexion and neck extension within both the control and the test groups, but no significant 


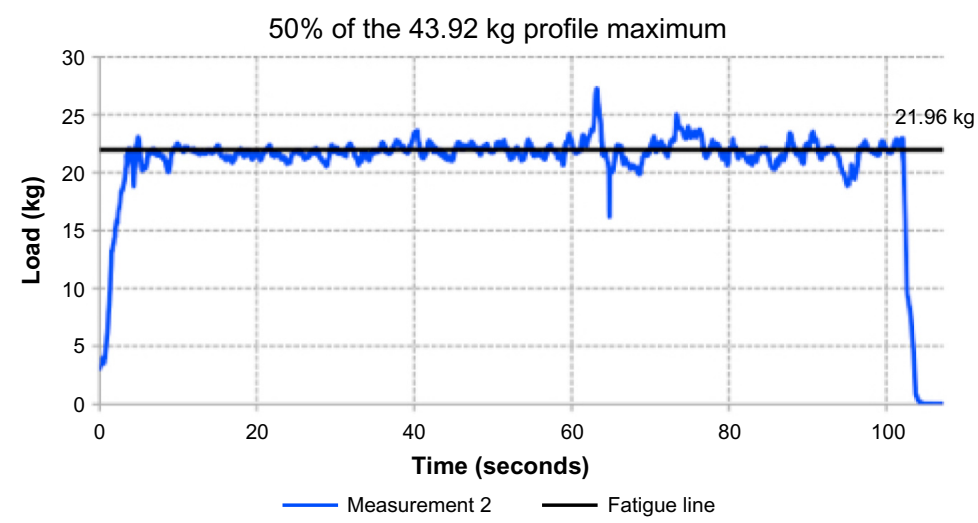

\begin{tabular}{|l|l|l|l|}
\hline Name & Area & Duration & Average \\
\hline Measurement 2 & $2,211.78 \mathrm{~kg} \cdot \mathrm{s}$ & $2 \mathrm{~m} \mathrm{47 \textrm {s }}$ & $20.60 \mathrm{~kg}$ \\
\hline
\end{tabular}

Figure 8 Measurement of fatigue, using $50 \%$ of maximum neck extension.

difference between the groups. There was a significant difference between groups in right rotation at retesting $(P=0.036)$. At retesting, the mean right rotation in the control group was significantly higher $\left(66.13^{\circ}\right)$ than in the test group $\left(62.13^{\circ}\right)$. The change in pre and post right rotation within each group was not significant. No other significant differences were found between the test and control group in the range of motion comparisons.

Table 2 shows the comparisons of right- and left-sided neck muscle strength (contralateral comparisons) and neck flexion versus neck extension (antagonistic comparisons), where flexion is taken as the agonist and extension as the antagonist. In the contralateral comparisons, no significant differences were found between the test and control groups.
A great deal of variability was seen in the outcomes within each group. In the antagonistic comparisons, no significant differences were found between the test and control groups.

Table 3 shows the neck muscle fatigue comparisons between the test and control groups. The fatigue area (kilograms - seconds) represents the area under the graph of load (kilograms) on the $y$-axis and time (seconds) on the $x$-axis. This test was performed using $50 \%$ of the previously recorded maximum neck extension. There were no significant differences between the groups in fatigue comparisons.

When looking at hand dominance, of the 32 players, $24(75 \%)$ were right-hand dominant, seven $(21.9 \%)$ were left-hand dominant, and one (3.1\%) admitted no hand dominance.

Table I Baseline characteristics and neck (cervical) range of movement

\begin{tabular}{|c|c|c|c|c|c|c|c|c|c|c|c|}
\hline & $\begin{array}{l}\text { Control } \\
\text { group } \\
\text { (pre) }\end{array}$ & $\begin{array}{l}\text { Control } \\
\text { group } \\
\text { (post) }\end{array}$ & $\begin{array}{l}\text { Total } \\
(\mathbf{N})\end{array}$ & $P$-value & $\begin{array}{l}\text { Mean } \\
\text { change }\end{array}$ & $\begin{array}{l}\text { Test } \\
\text { group } \\
\text { (pre) }\end{array}$ & $\begin{array}{l}\text { Test } \\
\text { group } \\
\text { (post) }\end{array}$ & $\begin{array}{l}\text { Total } \\
\text { (N) }\end{array}$ & $P$-value & $\begin{array}{l}\text { Mean } \\
\text { change }\end{array}$ & $\begin{array}{l}\text { Mean difference } \\
\text { test-control } \\
P \text {-value }\end{array}$ \\
\hline Height, cm & $|78.8|$ & 180.09 & 16 & 0.000 & 1.28 & 180.59 & 181.34 & 16 & 0.021 & 0.75 & 0.540 \\
\hline Weight, kg & 85.75 & 84.31 & 16 & 0.021 & -1.44 & 88.44 & 87.59 & 16 & 0.288 & -0.84 & 0.556 \\
\hline Neck circumference, cm & 36.72 & 37.56 & 16 & 0.116 & -0.84 & 37.97 & 37.38 & 16 & 0.345 & -0.59 & 0.832 \\
\hline Flexion, degrees & 34.44 & 43.13 & 16 & 0.007 & 8.69 & 35.81 & 44.44 & 16 & 0.002 & 8.63 & 0.658 \\
\hline Extension, degrees & 42.63 & 60.94 & 16 & 0.000 & $|8.3|$ & 46.13 & 59.50 & 16 & 0.000 & 13.38 & 0.532 \\
\hline $\begin{array}{l}\text { Right lateral flexion, } \\
\text { degrees }\end{array}$ & 39.00 & 40.38 & 16 & 0.267 & 1.38 & 38.63 & 38.50 & 16 & 0.954 & -0.13 & 0.431 \\
\hline $\begin{array}{l}\text { Left lateral flexion, } \\
\text { degrees }\end{array}$ & 37.13 & 41.88 & 16 & 0.004 & 4.75 & 38.50 & 41.63 & 16 & 0.170 & 3.13 & 0.927 \\
\hline $\begin{array}{l}\text { Right rotation, } \\
\text { degrees }\end{array}$ & 64.38 & 66.13 & 16 & 0.191 & 1.75 & 63.25 & 62.13 & 16 & 0.262 & -1.13 & 0.036 \\
\hline $\begin{array}{l}\text { Left rotation, } \\
\text { degrees }\end{array}$ & 63.88 & 67.00 & 16 & 0.059 & 3.13 & 63.75 & 64.63 & 16 & 0.460 & 0.88 & 0.431 \\
\hline
\end{tabular}

Note: Bold figure represents a significant value $(P<0.05)$. 
Table 2 Contralateral and antagonistic neck muscle comparisons

\begin{tabular}{|c|c|c|c|c|c|c|c|c|c|c|c|}
\hline & $\begin{array}{l}\text { Control } \\
\text { group } \\
\text { (pre) }\end{array}$ & $\begin{array}{l}\text { Control } \\
\text { group } \\
\text { (post) }\end{array}$ & $\begin{array}{l}\text { Total } \\
\text { (N) }\end{array}$ & $P$-value & $\begin{array}{l}\text { Mean \% } \\
\text { change }\end{array}$ & $\begin{array}{l}\text { Test } \\
\text { group } \\
\text { (pre) }\end{array}$ & $\begin{array}{l}\text { Test } \\
\text { group } \\
\text { (post) }\end{array}$ & $\begin{array}{l}\text { Total } \\
(\mathbf{N})\end{array}$ & $P$-value & $\begin{array}{l}\text { Mean \% } \\
\text { change }\end{array}$ & $\begin{array}{l}\text { Mean difference } \\
\text { test-control } \\
P \text {-value }\end{array}$ \\
\hline \multicolumn{12}{|c|}{ Contralateral neck muscle comparisons right versus left side in flexion, extension, and lateral (side) flexion } \\
\hline $\begin{array}{l}\text { Flexion with } \\
\text { left rotation, } \mathrm{kg}\end{array}$ & 20.27 & 21.54 & 16 & 0.141 & 8.46 & 21.57 & 24.44 & 16 & 0.008 & 16.86 & 0.064 \\
\hline $\begin{array}{l}\text { Flexion with } \\
\text { right rotation, } \mathrm{kg}\end{array}$ & 19.63 & 22.32 & 16 & 0.006 & 15.46 & 21.86 & 23.63 & 16 & 0.036 & 10.72 & 0.447 \\
\hline $\begin{array}{l}\text { Extension with } \\
\text { left rotation, kg }\end{array}$ & 30.87 & 36.02 & 16 & 0.002 & 16.07 & 31.42 & 35.92 & 16 & 0.004 & 20.08 & 0.972 \\
\hline $\begin{array}{l}\text { Extension with } \\
\text { right rotation, } \mathrm{kg}\end{array}$ & 31.03 & 35.22 & 16 & 0.005 & 13.66 & 31.64 & 35.83 & 16 & 0.011 & 18.07 & 0.793 \\
\hline $\begin{array}{l}\text { Left lateral } \\
\text { flexion, } \mathrm{kg}\end{array}$ & $30.05^{\dagger}$ & 35.63 & 16 & 0.007 & $21.73^{\dagger}$ & 33.40 & 39.95 & 16 & 0.004 & 22.77 & 0.115 \\
\hline $\begin{array}{l}\text { Right lateral } \\
\text { flexion, } \mathrm{kg}\end{array}$ & $32.32^{\ddagger}$ & 36.10 & 16 & 0.017 & $13.86^{\ddagger}$ & 33.13 & 39.16 & 16 & 0.042 & 13.77 & 0.222 \\
\hline \multicolumn{12}{|c|}{ Antagonistic neck comparisons neck flexion/agonist vs neck extension/antagonist } \\
\hline Flexion, kg & 22.22 & 24.99 & 16 & 0.003 & 14.72 & 24.60 & $27.70^{*}$ & 16 & 0.500 & $15.79 *$ & 0.175 \\
\hline Extension, $\mathrm{kg}$ & 36.82 & 41.25 & 16 & 0.005 & 13.28 & 38.77 & $45.65^{*}$ & 16 & 0.239 & $21.74 *$ & 0.114 \\
\hline
\end{tabular}

Notes: ${ }^{*} \mathrm{~N}=15 ;{ }^{+} \mathrm{N}=14 ;{ }^{*} \mathrm{~N}=13$.

\section{Discussion}

The only statistically significant result identified in our results between the test and control group was greater right neck rotation at retesting in the control group compared with the test group $(P=0.036)$. However, the change in pre- and posttesting right rotation within each group was not significant. Although this result is statistically significant, we do not believe this finding is of any clinical importance. There were significant differences within each of the groups for neck flexion and neck extension between the pre- and posttesting measurements. We believe this to be a result of user error in the pretesting recording, where the CROM device was used incorrectly and only the upper cervical spine movement was recorded, rather than full cervical spine movement. This was consistent between groups and was measured correctly in the retesting phase. There were no significant differences in neck flexion and extension between the groups.

Although there were no other statistically significant differences in neck strength, neck range of movement, and fatigability between the two groups, there were trends that could be of potential importance in an adequately powered study. This study is likely to be too underpowered to detect any significant differences between the test and control groups because of the small group sizes. There were trends identified in all areas tested.

\section{Contralateral (right vs left neck muscle strength) comparisons}

When looking at neck flexion with rotation, the mean percentage change was on average greater on the left (16.86) than on the right (10.72) side in the test group. In extension with rotation, the mean percentage change was on average greater in the test group for both the right (18.07 vs 13.66) and left (20.08 vs 16.07) sides compared with the control group. This was also seen in flexion with left rotation between groups. In flexion with left rotation, the mean percentage change was 16.86 in the test group and 8.48 in the control group. However, in flexion with right rotation, the percentage change was less than in the control group (10.72 vs 15.36). These findings with rotation further support the idea that right

Table 3 Neck muscle fatigability

\begin{tabular}{|c|c|c|c|c|c|c|c|c|c|c|c|}
\hline & $\begin{array}{l}\text { Control } \\
\text { group } \\
\text { (pre) }\end{array}$ & $\begin{array}{l}\text { Control } \\
\text { group } \\
\text { (post) }\end{array}$ & $\begin{array}{l}\text { Total } \\
\text { (N) }\end{array}$ & $P$-value & $\begin{array}{l}\text { Mean \% } \\
\text { change }\end{array}$ & $\begin{array}{l}\text { Test } \\
\text { group } \\
\text { (pre) }\end{array}$ & $\begin{array}{l}\text { Test } \\
\text { group } \\
\text { (post) }\end{array}$ & $\begin{array}{l}\text { Total } \\
\text { (N) }\end{array}$ & $P$-value & $\begin{array}{l}\text { Mean \% } \\
\text { change }\end{array}$ & $\begin{array}{l}\text { Mean difference } \\
\text { test-control } \\
P \text {-value }\end{array}$ \\
\hline $\begin{array}{l}\text { Fatigue area, } \\
\mathrm{kg} \cdot \text { seconds }\end{array}$ & I,659.23 & I,987.12 & 16 & 0.163 & 9.75 & $2,068.36$ & $2,022.14$ & 16 & 0.234 & 16.44 & 0.910 \\
\hline $\begin{array}{l}\text { Fatigue duration, } \\
\text { seconds }\end{array}$ & 100.35 & II5.05 & 16 & 0.134 & 10.29 & 107.28 & 107.03 & 16 & 0.255 & 13.20 & 0.970 \\
\hline
\end{tabular}

Note: Data presented as Median (interquartile range) and compared across groups using the Mann-Whitney U Test as not normally distributed. 
and left muscle imbalance is preexisting in the neck and that it can more likely than not be affected by focused exercises, particularly with neck extension. It was found that there was no correlation between neck muscle imbalance at the initial testing and hand dominance.

\section{Antagonistic (flexion vs extension) comparisons}

An increase in neck muscle strength was demonstrated, notably in neck extension (antagonist), in the test group $(21.74 \mathrm{~kg})$ compared with the control group (13.28 kg). This was also observed with neck flexion (agonist) with a mean percentage change of 15.79 in the test group and 14.72 in the control group.

\section{Fatigue}

The median percentage change of area was 16.44 in the test group and 9.75 in the control group. The median percentage change of duration was 13.20 in the test group compared with 10.29 in the control group. Although not statistically significant, it suggests that the training regime undertaken by the test group decreased the fatigability of the neck. That is to say, the neck becomes less susceptible to fatigue with training.

\section{Range of movement}

The range of movement outcomes are on average lower in the test group than the control group in all measurements. The largest change or reduction in range of movement between the test and control groups was observed in extension $\left(13.38^{\circ}\right.$ vs $18.31^{\circ}$ ), giving a mean difference of $4.93^{\circ}$ in favor of the control group. This adds further to the suggestion that focused training alters neck range of movement and that a reduction in range of movement may be beneficially protective.

The greatest increase in neck strength was seen in neck extension (antagonist), with a mean percentage difference of 8.46 (21.74 vs 13.28) between test and control. Neck extension revealed the greatest mean increase in strength and also the greatest mean reduction in movement (4.93 degrees). The inference is that by increasing neck strength, some range of movement is lost. However, Hamilton et $\mathrm{al}^{22}$ reported no correlation between neck muscle extension strength and neck range of movement in their study.

Other than the one player identified during enrolment, no other players were detected as having any underlying neck problems in the study. Specifically, there were no problems with the exercise program in the test group, and the feedback from the players was positive. As for what a "normal" neck profile is for this cohort of players, this study has shown a great deal of variability in range of movement and strength, which is consistent with the findings of Hamilton et al, ${ }^{22}$ who looked at a larger number of rugby players, including those of a similar age in Scottish schools. They reported an increase in neck extension strength with age, but with a large range at each age group studied.

There is little doubt that the neck is a vulnerable area in contact sports such as rugby, and injuries to the neck are potentially catastrophic. However, very little training time, either before or during the season, seems to be allocated to the neck. It has long been thought that the scrum was the main source of such injuries, although the tackle, or indeed any contact situation, also can result in serious neck injuries, so that any player, regardless of position, is at risk. ${ }^{7,10-14,19}$ McIntosh et $\mathrm{al}^{6}$ reviewed head, face, and neck injuries in Australian youth rugby. They found that the front row of the scrum had the greatest risk for neck injury, and forwards had a twofold increase in the rate of neck injury in comparison with the backs. Berry et al ${ }^{15}$ looked at cervical spinal cord injury in rugby union and rugby league in New South Wales, Australia, and found that the incidence of tetraplegia in rugby union was four times higher than in rugby league. For the six tetraplegic injuries in players aged younger than 18 years, there were three players in each code. The authors also noted that no scrum injuries occurred in rugby league after 1996, when the scrums became uncontested. The competitive scrum in rugby union is considered by many to be a fundamental part of the game, with uncontested scrums only being enforced under exceptional circumstances. A switch to uncontested scrums in rugby union, although possibly reducing injuries, is likely to significantly change the nature of the game. Furthermore, rucks and mauls are common in rugby union but do not take place in rugby league. It is important to note that Berry et al ${ }^{15}$ looked at data between 1986 and 2003. In recent years, there has been a move for rugby league coaches to switch codes and bring rugby league techniques and tactics to rugby union, notably in defence. In a rugby league tackle, the tackler's body is often more upright to wrap up the ball, compared with a traditional rugby union tackle, in which players are taught to go low, resulting in a bent or flexed body position. This application of rugby league techniques in rugby union may have an effect on the injuries sustained in the tackle situation.

This study has demonstrated that a tailored neck exercise program, which can be performed alongside a player's usual rugby training, produces a trend toward increasing neck strength and increasing the neck's resistance to fatigue. It may 
also produce a protective reduction in the range of neck movement. Although it cannot be proven that an increase in strength and resistance to fatigue might reduce the incidence of catastrophic neck injury, logic dictates that an individual with a weaker neck and who is susceptible to neck muscle fatigue may be more at risk of sustaining such injuries. Screening of the neck, although undertaken by a number of professional clubs, is not commonplace in rugby, nor is it currently easy to do. Specialist personnel and equipment are required. We have not demonstrated that screening the neck in rugby players aged 16 to 18 years detects undiagnosed injury or identifies those at particular risk.

This study has limitations. It is a pilot study with small sample sizes that is not powerful enough to detect significant differences between the groups. We deliberately chose a rugby playing school with motivated players and staff and recruited as many players as possible from the senior rugby squad. To ensure a comparable allocation of backs and forwards between the groups, we divided the players by position before randomization to the test and control groups. We relied on the players in the test group to complete the program as required, and they were mostly unsupervised. We also relied on the players in the control group to train as normal and not to try the program assigned to the test group. The intervention period of 6 weeks was chosen on the basis of the advice and experience of DG, who has been involved with numerous similar studies. This period may have been too short a time to detect significant differences between the groups. The size of the study groups precluded any accurate multivariable analysis, and as such, it was not possible to draw any accurate conclusions in differences between playing position (forwards and backs). Players in both groups trained and played as normal during the study period. The amount of rugby played by each player is likely to have varied, and this was not recorded. Forwards and backs have quite different roles in the game of rugby, and whereas all players are at potential risk for neck injury, those players in the backs generally take no part in scrums and, on the whole, are less involved in rucks and mauls than their forward counterparts. It might be assumed that as the forwards and backs in the test group underwent the same intervention, there would not be a difference between playing position in the results. In the same way that the game is different for the forwards, however, so are parts of their normal rugby training regime, which may have had an effect on the neck. Eliminating any other exercise that the players did during the study period would have reduced these confounding factors. With forwards reported to be more at risk for potential neck injury, perhaps more of their training should focus on the neck compared with those playing in back positions. Larger study numbers are needed to draw any conclusions.

\section{Conclusion}

This pilot study has shown that neck strength, range of movement, and susceptibility to fatigue can be influenced using a focused neck training regime. It forms an important basis for a larger, multicenter study to aim to prove significant differences and to ensure that the neck is given due attention in rugby training and receives the same focus of conditioning as other parts of the body. This should provide compelling evidence and incentive for the introduction of focused neck exercise programs as part of pre- and intraseason training at all levels of youth rugby. Because injuries to the neck, although rare, are potentially catastrophic, any measures that serve to protect this vulnerable area and reduce risk can only be of benefit to all involved in the sport.

\section{Acknowledgments}

The initial statistical analysis was performed by Dr Suzie Cro, statistician at the Medical Research Council, London. During the revision of the manuscript, statistical analysis was performed by Dr Erica Cook, from the Department of Psychology, University of Bedfordshire. Professor Gordon Blunn, director of the Institute of Orthopaedics and Musculoskeletal Science, Royal National Orthopaedic Hospital Stanmore, Middlesex, United Kingdom, was involved in the concept and design of the study and financially supported the study. We also thank Mr Barry Burgess, head of sport at Bedford School, Bedford, United Kingdom, for all of his help in setting up and overseeing parts of the study. Many other people contributed to the execution of the project; for example, Don Gatherer's assistants and the school personnel. We gratefully acknowledge their contributions. The Consolidated Standards of Reporting Trials Statement was used as a reference for the study writeup. ${ }^{25}$ The harnesses used in this study were funded by Professor Gordon Blunn. This trial was registered with the National Ethics Research Service, reference number 10/H0721/60.

\section{Disclosure}

The authors report no conflicts of interest in this work.

\section{References}

1. Garraway WM, Lee AJ, Hutton SJ, Russell EB, Macleod DA. Impact of professionalism on injuries in rugby union. Br J Sports Med. 2000;34(5): $348-351$ 
2. Targett SG. Injuries in professional Rugby Union. Clin J Sport Med. 1998;8(4):280-285.

3. Fuller CW, Raftery M, Readhead C, Targett SG, Molloy MG. Impact of the International Rugby Board's experimental law variations on the incidence and nature of match injuries in southern hemisphere professional rugby union. S Afr Med J. 2009;99(4):232-237.

4. Brooks JH, Kemp SP. Injury-prevention priorities according to playing position in professional rugby union players. Br J Sports Med. 2011; 45(10): 765-775.

5. Haseler CM, Carmont MR, England M. The epidemiology of injuries in English youth community rugby union. Br J Sports Med. 2010;44(15): 1093-1099.

6. McIntosh AS, McCrory P, Finch CF, Wolfe R. Head, face and neck injury in youth rugby: incidence and risk factors. $\mathrm{Br} J$ Sports Med. 2010;44(3):188-193.

7. Bathgate A, Best JP, Craig G, Jamieson M. A prospective study of injuries to elite Australian rugby union players. Br J Sports Med. 2002; 36(4):265-269.

8. Brooks JH, Fuller CW, Kemp SP, Reddin DB. A prospective study of injuries and training amongst the England 2003 Rugby World Cup squad. Br J Sports Med. 2005;39(5):288-293.

9. Jakoet I, Noakes TD. A high rate of injury during the 1995 Rugby World Cup. SAfr Med J. 1998;88(1):45-47.

10. Fuller CW, Ashton T, Brooks JH, Cancea RJ, Hall J, Kemp SP. Injury risks associated with tackling in rugby union. Br J Sports Med. 2010; 44(3):159-167.

11. Lee AJ, Garraway WM. Epidemiological comparison of injuries in school and senior club rugby. Br J Sports Med. 1996;30(3):213-217.

12. Lee AJ, Myers JL, Garraway WM. Influence of players' physique on rugby football injuries. Br J Sports Med. 1997;31(2):135-138.

13. Brooks JH, Fuller CW, Kemp SP, Reddin DB. Epidemiology of injuries in English professional rugby union: part 1 match injuries. Br J Sports Med. 2005;39(10):757-766.

14. Brooks JH, Fuller CW, Kemp SP, Reddin DB. Epidemiology of injuries in English professional rugby union: part 2 training Injuries. Br J Sports Med. 2005;39(10):767-775.
15. Berry JG, Harrison JE, Yeo JD, Cripps RA, Stephenson SC. Cervical spinal cord injury in rugby union and rugby league: are incidence rates declining in NSW? Aust N Z J Public Health. 2006;30(3):268-274.

16. Fuller CW. Catastrophic injury in rugby union: is the level of risk acceptable? Sports Med. 2008;38(12):975-986.

17. Noakes T, Jakoet I. Spinal cord injuries in rugby union players. $B M J$. 1995;310(6991):1345-1346.

18. Banerjee R, Palumbo MA, Fadale PD. Catastrophic cervical spine injuries in the collision sport athlete, part 1: epidemiology, functional anatomy, and diagnosis. Am J Sports Med. 2004;32(4):1077-1087.

19. Shelly MJ, Butler JS, Timlin M, Walsh MG, Poynton AR, O'Byrne JM. Spinal injuries in Irish rugby: a ten-year review. J Bone Joint Surg Br. 2006;88(6):771-775.

20. Reporting Procedure for Rugby-related Catastrophic and Fatal Injuries. International Rugby Board; 2010-2013. Available from: http://www. irbplayerwelfare.com/?documentid=11. Accessed June 11, 2013.

21. Catastrophic Injury Task Group. Report to Management Board. Rugby Football Union; April 2007. Available from: http://www. irbplayerwelfare.com. Accessed June 11, 2013.

22. Hamilton DF, Gatherer D, Jenkins PJ, et al. Age-related differences in the neck strength of adolescent rugby players: A cross-sectional cohort study of Scottish schoolchildren. Bone Joint Res. 2012;1(7): $152-157$.

23. Hamilton DF. Simpson HR, Gatherer D. Repeatability and InterTester Reliability of a New Tool to Assess Isometric Neck Strength in Adolescents. Middlesbrough: Procs Physiotherapy Research Society; 2010.

24. Rubin DB. Inference and missing data. Biometrika. 1976;63(3): 581-592.

25. Schulz KF, Altman DG, Moher D; CONSORT Group. CONSORT 2010 statement: updated guidelines for reporting parallel group randomized trials. Ann Intern Med. 2010;152(11):726-732.
Open Access Journal of Sports Medicine

\section{Publish your work in this journal}

Open Access Journal of Sports Medicine is an international, peer-reviewed, open access journal publishing original research, reports, reviews and commentaries on all areas of sports medicine. The manuscript management system is completely online and includes a very quick and fair peer-review system.

\section{Dovepress}

Visit http://www.dovepress.com/testimonials.php to read real quotes from published authors. 